\title{
Management of Infantile Spasms: An Updated Review
}

\author{
Mary lype ${ }^{1} \quad$ Kiren George Koshy ${ }^{2}$ \\ ${ }^{1}$ Department of Pediatric Neurology, Government Medical College, \\ Kerala, India \\ 2Department of General Medicine, Government Medical College \\ Trivandrum, Trivandrum, India
}

\author{
Address for correspondence Mary lype, MD, DM, Government \\ Medical College Trivandrum, TC 4/2559(1), Pattom-Kawdiar Road, \\ Kawdiar PO, Trivandrum 695003, Kerala, India \\ (e-mail: maryiypedr@gmail.com).
}

Int J of Ep:2020;6:4-14

\begin{abstract}
Infantile spasms remain the most challenging of the epileptic encephalopathies of childhood. Infantile spasms are classified as an epileptic encephalopathy, as the adverse cognitive and behavioral burden of the condition is out of proportion to the burden one would expect from the underlying etiology or the accompanying magnetic resonance imaging. The ictal and interictal electroencephalographic (EEG) activity is presumed to contribute to the progressive cerebral dysfunction. In many of these children, the underlying etiology also contributes to the severe mental subnormality and autistic behavior. Though it is the syndromic approach that guides the pediatric epileptologist, it is best to keep in mind that one syndrome may evolve into another in infancy and early childhood. A baby with Ohtahara syndrome may, after 2 to 7 months, begin to have spasms. Lennox-Gastaut syndrome with its typical seizure types and EEG may evolve in a child with infantile spasms. The unique modalities used in the treatment of infantile spasms make early recognition important. It is, however, also of paramount importance to make an etiological diagnosis as the underlying etiology may be eminently treatable. The treating physician cannot abandon them as wholly "intractable" epilepsy. The excellent response to treatment in the few who just cannot be defined or accurately predicted drives the physician to exercise his brain. Use of

Keywords

- infantile spasms

- adrenocorticotrophic hormone

- vigabatrin the two well-accepted modalities of treatment; vigabatrin and adrenocorticotrophic hormone singly or in combination, oral steroids in high dose, ketogenic diet, the conventional antiepileptic medications, and strategies to target the basic cause have been tried out by various clinicians. Here, we have made an attempt to collate evidence and describe the progress in the management of infantile spasms.
\end{abstract}

\section{Introduction}

Infantile spasms (IS) has been described in the International League Against Epilepsy (ILAE) 2017 operational classification of seizure types as epileptic spasms occurring at infantile age. They are further defined as "sudden flexion, extension or mixed extension-flexion of predominantly proximal and truncal muscles." ${ }^{1}$ Hypsarrhythmia (the signatory electroencephalographic [EEG] finding of IS) may be "modified" with increased interhemispheric synchrony, asymmetry, fragmentation, a consistent focus of abnormal discharge or may consist of only high voltage asynchronous slow activity.
The term "epileptic spasm" is now preferred on recognition that spasms can present for the first time beyond infancy. An age-related epileptic encephalopathy, IS has an onset between 3 months and 2 years with an estimated incidence of 0.25 to 0.42 per 1,000 live births per year. ${ }^{2}$

IS remain etiologically heterogeneous. The etiology is identified in 60 to $75 \%$ of cases with relevant radiological, infectious, and metabolic investigations. ${ }^{3}$ Neurocutaneous syndromes, brain malformations, neonatal strokes, and sequelae of hypoxic ischemic encephalopathy are often obvious on a magnetic resonance imaging (MRI). Tuberous sclerosis (TS), the most well-known genetic association with IS, 
occurs in only 1 to $19 \%$ of children with IS., ${ }^{2,3}$ Array comparative genomic hybridization (aCGH), in a 2014 report from Canada, has revealed several de novo and likely pathogenic hemizygous variants in 7\% of children. ${ }^{4}$ Many of these variants are also associated with intellectual disability or autism spectrum disorder with no seizures. Though more expensive, and with a delayed yield, whole exome sequencing is always found to have a greater yield than targeted gene sequencing in these children. ${ }^{4}$ Pathogenic mutations have been reported in ARX, STXB1, SLC2A1, CASK, ALG13, PNPO, CDKL5, MAGI2, SCN1A, SCN2A, STK9, DCX, and ADXL genes..$^{3-7}$

Though diverse modalities have been used for the treatment of IS, the success in terms of seizure control, motor outcome, and cognition is poor. ${ }^{8,9}$ The two modalities that have opened up lighted avenues are hormonal treatment and vigabatrin. These promising agents let down the clinician from time to time and fail to control seizures. In those children who achieve seizure freedom, the cognitive outcome remains poor. ${ }^{8,9}$ Adrenocorticotropic hormone (ACTH) in its natural and synthetic forms and oral prednisolone has been used as hormonal therapy. Very few randomized controlled trials, with small numbers and poor methodology, have been done using the various agents in children with IS. The answer to what is the optimal treatment for IS is yet to come.

\section{Investigations in a Child with Infantile Spasms}

Role of neuroimaging in these children is later elaborated. The National Infantile Spasms Consortium has observed that 55\% of patients reach an etiological diagnosis following clinical examination and MRI. They have proposed a cost-effective workup of children with no detected etiology, to include aCGH followed by an epilepsy gene panel if the microarray is not diagnostic, serum lactate, serum amino acids, and urine organic acids. ${ }^{10}$

\section{Treatment Modalities Available}

\section{Adrenocorticotropic Hormone}

The Cochrane review of 2013 cautions the comparison of different studies with ACTH; as natural or synthetic ACTH has been used by different groups and the two cannot be compared. ${ }^{11}$ However, Riikonen states that the international units of the two forms of ACTH are equivalent. ${ }^{12}$ Shortterm treatment with high-dose intramuscular natural ACTH $\left(150 \mathrm{IU} / \mathrm{m}^{2}\right)$ in two divided doses may help to treat IS and is the Food and Drug Administration (FDA)-approved dose.

There is modest evidence that low-dose ACTH is as effective as high dose. ${ }^{13-15}$ However, ACTH is not without side effects ( - Table $\mathbf{1}$ ). The duration for which ACTH should be given is also not agreed upon. ACTH is available in the natural form; it is made from bovine and porcine sources. With the scare of bovine spongiform encephalopathy in Europe, the natural form ceased to be marketed there and the synthetic form was used either in depot (given on alternate days) or nondepot form. In the updated evidence-based guideline developed by the American Academy of Neurology (AAN) and the Practice Committee of the Child Neurology society in 2012, it is stated that, "ACTH is more effective than vigabatrin for short-term treatment of infantile spasms." ${ }^{16}$ It was approved for use in children with IS by the US FDA in 2010. - Fig. 1 is a description that consolidates the gamut of doses of different modalities used in IS.

Table 1 Standard modalities used to treat infantile spasms

\begin{tabular}{|c|c|c|c|}
\hline & Advantages & Adverse effects & Precautions \\
\hline ACTH & Has best evidence & $\begin{array}{l}\text { Death is recorded in many studies. It may cause } \\
\text { hypertension, hyperglycemia, irritability, pigmen- } \\
\text { tation, electrolyte imbalance, weight gain and } \\
\text { facial puffiness, severe life-threatening or other } \\
\text { infections due to immunosuppression, gastritis, } \\
\text { sleep disturbance, reversible hypertrophic cardio- } \\
\text { myopathy, and cerebral cortical atrophy }\end{array}$ & $\begin{array}{l}\text { Use } \mathrm{H} 2 \text { blocker or proton pump } \\
\text { inhibitor, monitor blood pressure (once } \\
\text { daily for } 2 \text { days and weekly thereafter), } \\
\text { and blood sugar (check at } 48 \text { hours } \\
\text { and weekly thereafter). Avoid live-virus } \\
\text { vaccines for } 4 \text { weeks following course. } \\
\text { Stress dose steroid may be needed in } \\
\text { case of intercurrent illness }\end{array}$ \\
\hline Vigabatrin & $\begin{array}{l}\text { More effective than } \\
\text { ACTH in tuberous } \\
\text { sclerosis } \\
\text { Oral administration }\end{array}$ & $\begin{array}{l}\text { Black box warning regarding irreversible, loss of } \\
\text { vision in the peripheral visual field. Behavioral } \\
\text { abnormality, psychosis, somnolence, depression, } \\
\text { irritability, myoclonus, diarrhea, anemia, deranged } \\
\text { liver function tests and reversible hyperintensities } \\
\text { in white matter, thalamus, basal ganglia, and brain } \\
\text { stem }\end{array}$ & $\begin{array}{l}\text { Periodic testing by an ophthalmologist } \\
\text { to look for macular changes. Restrict use } \\
\text { of the drug for } 6-12 \text { months }\end{array}$ \\
\hline Oral steroid & Oral administration & $\begin{array}{l}\text { Weight gain, immunosuppression, gastritis, } \\
\text { irritability, sleep disturbance, hyper pigmentation, } \\
\text { reversibly hypertrophic cardiomyopathy, and } \\
\text { cerebral cortical atrophy }\end{array}$ & $\begin{array}{l}\text { Use } \mathrm{H} 2 \text { blocker or proton pump } \\
\text { inhibitor, monitor blood pressure and } \\
\text { blood sugar. Avoid live-virus vaccines } \\
\text { for } 4 \text { weeks following course. Stress } \\
\text { dose steroid may be needed in case of } \\
\text { intercurrent illness }\end{array}$ \\
\hline
\end{tabular}

Abbreviation: ACTH, adrenocorticotrophic hormone. 


\section{Treatment}
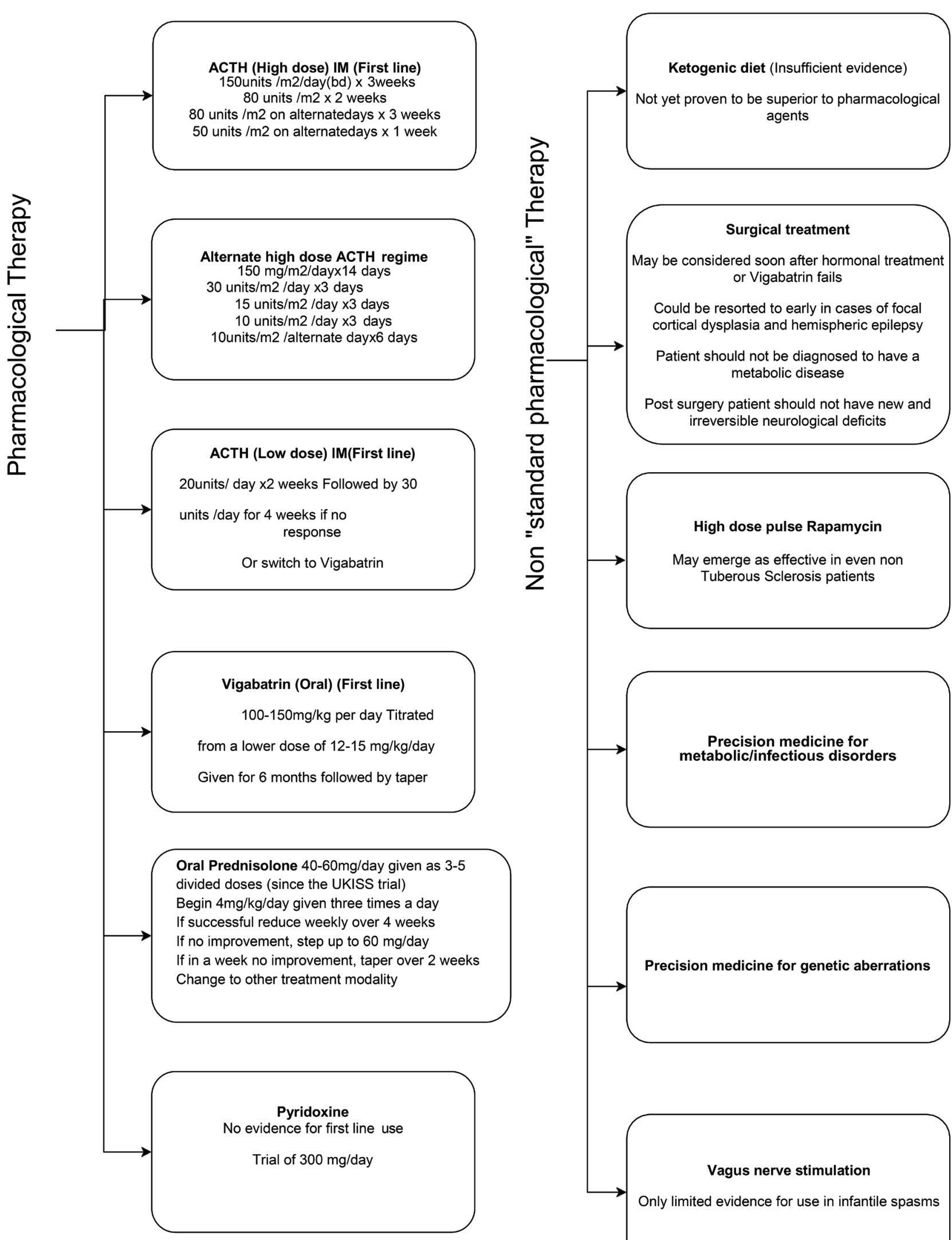

Oral Prednisolone $40-60 \mathrm{mg} /$ day given as 3-5 (since the UKISS trial)

fuccessful reduce weekly over 4 weeks

Change to other treatment modality

Pyridoxine

Trial of $300 \mathrm{mg} /$ day

Vagus nerve stimulation

Only limited evidence for use in infantile spasms

continued 


\section{Subsequent oral adjunctive therapies}

Insufficient evidence; Often used in intractable cases, for prevention of relapse and in continuation phase

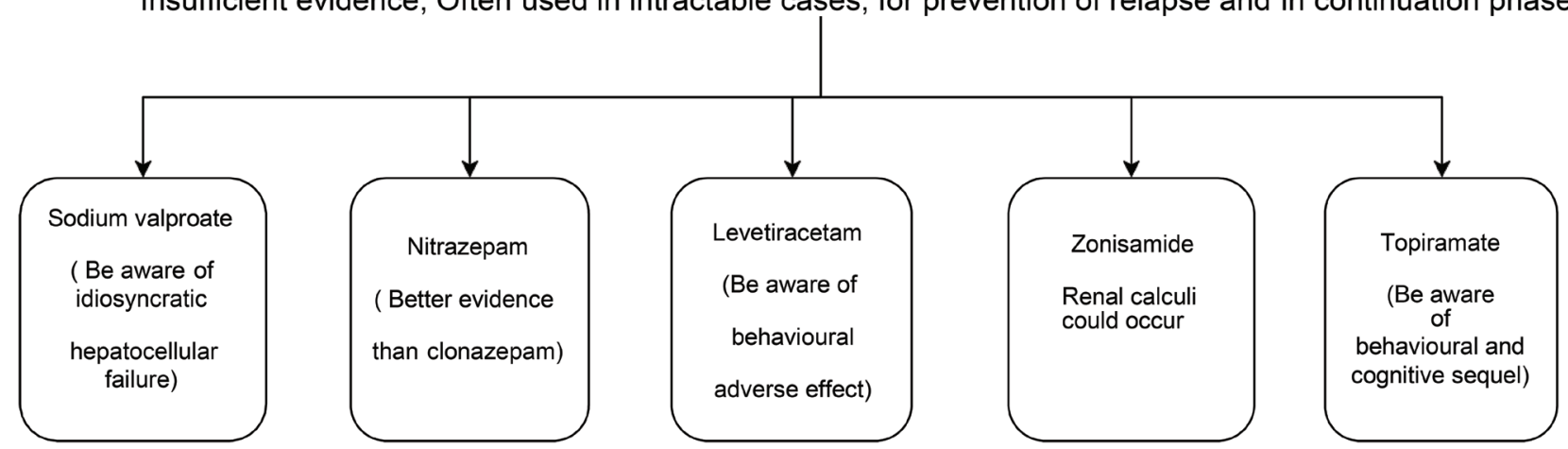

Fig. 1 Treatment options in infantile spasms. ACTH, adrenocorticotrophic hormone.

\section{Vigabatrin}

Vigabatrin, a suicide substrate for the enzyme gamma aminobutyrate transaminase, effectively blocks it and thus augments the brain level of gamma aminobutyric acid. It produces irreversible visual field defects and has psychiatric side effects, which has stuttered its entry into the epileptic armamentarium. ${ }^{17,18}$ The United States especially resisted its entry as intramyelinic edema in the brain was demonstrated in animals. ${ }^{19}$ The AAN in their 2012 meta-analysis failed to show that vigabatrin is superior to ACTH and recommended that ACTH or vigabatrin may be used for short-term treatment of IS. ${ }^{16}$ They also recommend ACTH over vigabatrin to possibly improve the developmental outcome (level C evidence). ${ }^{16}$

The United Kingdom Infantile Spasms Study (UKISS trial) compared hormonal treatment (oral prednisolone or ACTH) and vigabatrin. ${ }^{20-22}$ Spasm cessation on day 14 was more likely in children on hormonal treatment. ${ }^{20}$ At 14 months, seizure freedom and developmental outcome assessed using Vineland Adaptive Behavior Scale (VABS) were comparable in the two groups. ${ }^{21}$ However, developmental outcome was better in children with cryptogenic IS, given ACTH versus those given vigabatrin. At 4 years follow-up, developmental and epilepsy outcome between the two treatment groups were not significantly different and developmental outcome continued to be better in children with cryptogenic spasms given hormonal treatment. ${ }^{22}$ Children with TS were excluded in this study and thus the real advantage of vigabatrin may have been hidden by excluding the group that is accepted to be best treated with vigabatrin.

Chiron et al compared vigabatrin (150 mg/kg/day) to hydrocortisone $(15 \mathrm{mg} / \mathrm{kg} /$ day) in children with TS and showed that all children who were first treated with vigabatrin (11/11) became spasm free compared with 5/11 on hydrocortisone. Nonresponders to hydrocortisone were crossed over to vigabatrin and all of them became seizure free. ${ }^{23}$ This was the paper that first established the role of vigabatrin in children with TS. A nonrandomized study by
Ahmed showed earlier and better EEG outcome with ACTH, though seizure control was better with vigabatrin. ${ }^{24}$

In spite of the formidable list of adverse effects (- Table 1) associated with it, vigabatrin was approved for use by the US FDA in 2009 for refractory complex partial seizures and IS based on two studies conducted by Elterman et al..$^{25,26}$ Elterman et al in 2010 published evidence, after a single blind randomized control trial, of better seizure outcome with high-dose vigabatrin (up to $200 \mathrm{mg} / \mathrm{kg} /$ day) compared with low dose. ${ }^{27}$ The current guideline is an ophthalmological evaluation once in every 3 months for children on vigabatrin. ${ }^{28}$

\section{Oral Prednisolone}

The protocol used in the UKISS trial (40-60 mg/day of oral prednisolone given as 3-5 divided doses) has been since used in the International Collaborative Infantile Spasms Study (ICISS) trial and by Wanigasinghe et al..$^{20,29,30}$ Hussain et al modified this dose to $8 \mathrm{mg} / \mathrm{kg}$ per day. ${ }^{31}$ An Indian study showed a $4 \mathrm{mg} / \mathrm{kg}$ dose to be more effective on day 14 compared with a $2 \mathrm{mg} / \mathrm{kg}$ dose. ${ }^{32}$

The randomized controlled trial by Wanigasinghe et al showed that prednisolone has more efficacy than ACTH for control of IS at 14-day, 3-month, 6-month, and 12-month follow-up. However, on follow-up beyond 12 months there was no statistical difference between the two groups ${ }^{30}$ The UKISS trial did not show any difference between groups given highdose prednisolone and ACTH. ${ }^{31}$ Hussain et al, using historical controls, demonstrated that very high-dose prednisolone is superior to low-dose prednisolone but less effective than highdose ACTH. ${ }^{31}$ Kossoff et al showed that high-dose prednisolone is not inferior to ACTH. ${ }^{33}$ The national IS consortium, however, showed a better response to ACTH when compared with vigabatrin and oral steroids with very minimal response to nonstandard treatments. ${ }^{34}$ A retrospective case series from Australia showed superiority of oral prednisolone over vigabatrin. ${ }^{35}$

The AAN in their meta-analysis in 2012 revealed insufficient evidence to recommend use of prednisolone, 
dexamethasone, and methylprednisolone as being as effective as ACTH for the management of IS. ${ }^{16}$

\section{Ketogenic Diet}

A high-fat and low-carbohydrate diet has been used in intractable epilepsy since the early 20th century. Several authors have shown positive results with ketogenic diet (KD) in intractable IS. ${ }^{36-38}$ Hong et al in her prospective study demonstrated seizure freedom of $37 \%$ over a 6 -month period. ${ }^{36}$ Kayyali et al found KD effective in $70 \%$ at 3 months (15\% maintaining the seizure free status at 6 months). ${ }^{37}$ Kang et al showed that short-term use of KD was as good as a longer duration of the same, as recurrence of spasms was comparable after KD for 1 year versus for 2 years. ${ }^{38}$ There is also consensus of opinion that KD is the treatment of choice when the etiology is pyruvate dehydrogenase complex deficiency or glucose transporter type 1 (Glut1) deficiency.,39 Updated recommendations of the International Ketogenic Diet Study Group have also recommended that KD should be initiated early when the child with IS has TS or a gastrostomy tube. ${ }^{38,40 \text {, }}$ However, there are concerns about this diet hampering growth in the developing child. ${ }^{36}$ Evidence supporting use of KD in early life is mounting. ${ }^{41,42}$ Dressler et al have recently shown a trend toward lower relapse rates with KD especially when given following vigabatrin. ${ }^{43}$

Better cognitive development is documented in children on KD versus those on hormonal treatment or vigabatrin. ${ }^{36}$ Rigorous KD is not without side effects and often poorly tolerated. Modified Atkins diet and the simplified modified Atkins diet have been shown to be effective in controlling seizures in children with IS. ${ }^{44,45}$ In a recent retrospective analysis, only 2 out of 22 children with refractory IS responded to $\mathrm{KD}$, and the response was maintained only for 1 month. The diet could be maintained in only $6 / 22$ patients with partial or subjective benefit. ${ }^{46}$

\section{Role of Pyridoxine}

There is insufficient evidence to support the use of pyridoxine in the long-term treatment of IS. ${ }^{16}$ In cases where no cause is apparent for spasms, pyridoxine-dependent seizures may be suspected and a trial of pyridoxine in the pharmacological dose of $300 \mathrm{mg} /$ day may be given a trial. ${ }^{47}$ In suspected cases, it would be best to look for pipecolic acid, piperideine6 -carboxylate, and $\alpha$ aminoadipic semialdehyde in quickly frozen plasma using liquid chromatography-mass spectrometry. A genetic study for ALDH7A1 mutation may also be done.

\section{mTOR Inhibitors for Tuberous Sclerosis}

Sirolimus is a mammalian target of rapamycin (mTOR) inhibitor available as tablet and solution that is rapidly absorbed. Everolimus, another mTOR inhibitor with greater bioavailability, is initiated at $5 \mathrm{mg} / \mathrm{m}^{2} /$ day given once daily and titrated to a target blood level of 5 to $15 \mathrm{ng} / \mathrm{mL}$. High-dose pulse rapamycin, an mTOR pathway inhibitor that is well tolerated, may in future emerge as the new and effective therapy for IS, even when not due to TS. ${ }^{48,49}$
A recent comprehensive review by Li et al has shown that seizure frequency is significantly reduced in patients with TS given mTOR inhibitors. ${ }^{50}$ mTOR inhibition should be the subject of future trials as this therapeutic modality addresses the potentially lethal complications of TS including subependymal giant cell astrocytoma related hydrocephalus, hemorrhage due to renal angiomyolipoma and progressive lymphangioleiomyomatosis, besides seizure control. ${ }^{51}$

\section{Targeting Other Metabolic Causes}

An underlying metabolic etiology has been reported variably as $8,4.8$, and $12.5 \% .^{8,10,52}$ Phenylketonuria (PKU), cobalamin deficiency, methylmalonic aciduria, Glut1 deficiency, pyridoxine deficiency or dependency, pyridoxal 5'P deficiency, folinic acid deficiency, propionic academia, homocystinemia, biotinidase deficiency, primary carnitine deficiency, molybdenum cofactor deficiency, Menkes kinky hair disease, and mitochondrial disorders including pyruvate dehydrogenase deficiency, Leigh's disease, and Alpers-Huttenlocher disease are some of the metabolic disorders that can be treated. There are no studies comparing standard treatment for IS and precision treatment for the underlying neurometabolic disease in children with IS. A Saudi Arabian group has shown a poor response to treatment using steroids or vigabatrin in children with IS and a neurometabolic disorder. ${ }^{52}$

Nonketotic hyperglycinemia (NKH), PKU, Menkes disease, pyridoxine responsive or dependent seizures, methylmalonic aciduria, and mitochondrial disorders were found to be more frequently seen in infants with IS in a recent review. ${ }^{53}$ In children with KCNT1 mutation, treatment with quinidine is effective. ${ }^{54}$ Though apnea improves in children with $\mathrm{NKH}$ when given sodium benzoate and ketamine, seizure control and developmental milestones are rarely achieved. ${ }^{55}$ Menkes disease also has poor seizure control even after copper histidinate supplementation. ${ }^{56}$

\section{Other Treatable Underlying Etiologies}

In children with IS and cytomegalovirus infection, 10/22 maintained seizure freedom over 18 months on treatment with intravenous ganciclovir given for 3 to 12 weeks along with antiepileptic drugs. ${ }^{57}$ Riikonen has always cautioned against the use of ACTH in children with spasms and cytomegalovirus infection as she documented worsening of spasms with ACTH. ${ }^{58}$

\section{Nonstandard Treatment for Infantile Spasms}

The 2012 AAN recommendation states insufficient evidence to recommend sodium valproate, nitrazepam, levetiracetam, zonisamide, topiramate, and KD for the management of IS. ${ }^{16}$ Topiramate is the most promising among other antiepileptics. ${ }^{59,60}$ Knupp et al have recently shown that when a firstline standard-therapy for IS (ACTH, oral steroid or vigabatrin) fails, the use of a second standard-therapy (ACTH, oral steroid, or vigabatrin) with a different mechanism of action is superior to using another antiepileptic drug like topiramate or zonisamide. ${ }^{6}$ 


\section{Available Evidence for the Dose of ACTH and the Issue of Combining Steroid with Vigabatrin}

A retrospective study showed that though the immediate effect of high-dose ACTH is more impressive, long-term outcome after high- or low-dose ACTH is comparable. ${ }^{62}$ Similar results, with no significant difference in seizure outcome with even very low dose of ACTH, were supported by others. ${ }^{13-15}$ However, a better seizure control has been highlighted with high-dose ACTH by other authors. ${ }^{63,64}$ The high-dose group showed a higher rate of hypertension on treatment, with other side effects comparable between high and low dose. ${ }^{64}$ Long-term weekly ACTH has been used successfully in some series. ${ }^{65}$

The ICISS trial published its results in 2017 and revealed that hormonal treatment with concomitant vigabatrin is more effective in controlling seizures than hormonal treatment alone. ${ }^{29}$ Infants with IS and a hypsarrhythmic or similar EEG were randomly assigned in a one to one ratio to either hormonal therapy with vigabatrin or hormonal therapy alone. Hormonal treatment included prednisolone used in a minimum dose of $40 \mathrm{mg}$ daily or intramuscular ACTH 40 units on alternate days. Vigabatrin was used in a dose of $100 \mathrm{mg} / \mathrm{kg} /$ day. No witnessed spasms between day 14 and day 42 (a 4-week period) were taken as seizure freedom. Infection as an adverse effect was seen in five patients on hormonal treatment alone and four on combination treatment. This study did not randomize hormonal treatment and therefore it is not clear whether it is better to combine oral steroid or ACTH with vigabatrin. At follow-up of this cohort at 18 months, no difference in VABS scores or seizure outcome was seen in the two groups. ${ }^{66}$ Analysis of the same data has shown that it is initial control of seizure between 14 and 42 days that predicted a better VABS score and seizure freedom at 18 months. ${ }^{66} \mathrm{~A}$ shorter latent period to initiate treatment also resulted in better seizure outcome and VABS score. ${ }^{66}$ This merits more research, using ACTH with vigabatrin versus ACTH or vigabatrin alone, as many investigators continue to believe that ACTH is superior to oral steroids. . $^{1620,67}$

Recently, rapid control of seizures has been seen with pulse methyl prednisolone for 3 days followed by 56 days of high-dose oral prednisolone. ${ }^{68,69}$ However, these studies have no power, as numbers recruited were small and there was no control group.

\section{Cochrane Review}

A recent Cochrane review has concluded that hormonal treatment (ACTH or prednisolone) results in faster spasm control in more children. ${ }^{11}$ They are skeptical about better long-term seizure or cognitive outcome. There is modest evidence for better developmental outcome in those with no underlying neurological disease. They stress that when prednisolone or vigabatrin is used, the dose should be high and that optimum dose of ACTH is not yet clear. It is observed that vigabatrin should possibly be the treatment in TS and that it is not clear, based on evidence, whether it is necessary to treat persisting EEG abnormalities when the child is seizure free. No other treatment other than hormonal treatment or vigabatrin can be recommended on the basis of evidence. ${ }^{11}$

\section{Prevention of Relapse and Duration of Treatment}

It is well known that remitted spasms relapse often after a time interval. ${ }^{70}$ Knupp et al have clearly shown that use of a second standard-therapy with a different mechanism of action is better than another antiepileptic medication. ${ }^{61}$ The EEG at control of spasms has been evaluated by a group from Japan. ${ }^{71}$ Their results showed that chances of relapse are $17 \%$ with normal EEG at seizure control, $75 \%$ with nonhypsarrhythmic epileptic activity, and $86 \%$ with hypsarrhythmia. This study lends support to the opinion that treatment should be continued until the EEG has normalized.

\section{Time Lag to Treatment}

A shorter time lag to treatment has been generally accepted, leading to a better outcome in these children. ${ }^{16,66}$ However, this correlation was not seen in other studies. ${ }^{8}$

\section{Brain Imaging}

In a retrospective review by Khatami et al, MRI of the brain helped to establish the etiology in $73 \%{ }^{72} \mathrm{He}$ has demonstrated that one-third of cases considered idiopathic on clinical assessment are classified as structural-metabolic following MRI and that the MRI finding cannot predict the treatment response. ${ }^{72}$ There could be clues in the MRI pointing to an inborn error of metabolism. ${ }^{73}$ As the immature white matter could hide subtle dysplasias serial MRI would be needed in intractable cases that show focal EEG changes, to consider whether surgical resection would lead to seizure freedom. ${ }^{74}$

Positron emission tomogram (PET) may reveal areas of hypometabolism, in patients with a normal MRI, but with focal EEG changes, enabling remission following surgery done based on PET localization. ${ }^{75}$ Glucose metabolism PET scan $\left({ }^{18} \mathrm{~F}\right.$ - fluorodeoxyglucose [FDG] PET) is routinely used; though some have used ${ }^{11} \mathrm{C}$-flumazenil or ${ }^{11} \mathrm{C}$ - $\alpha$-methyl-L-tryptophan PET scans for better localization of cortical tubers and dysplasias. ${ }^{76}$

Better localization of the epileptic focus is achieved with the aid of ictal and interictal single-photon emission computed tomography (SPECT). Interictal SPECT images are subtracted from ictal SPECT images and then displayed on co-registered MRIs (subtraction ictal single photon emission computed tomography co-registered to magnetic resonance imaging [SISCOM] analysis) for greater sensitivity and accuracy. When the first ictal SPECT image is nonlocalizing, repeated ictal SPECT studies with SISCOM analysis help refine the attempt to localize the epileptic focus. ${ }^{77}$

\section{Surgical Treatment}

Surgery is no longer a last resort and should be the option considered soon after the child fails hormonal treatment or vigabatrin or a cross over. It should be resorted to as early as possible in children with focal brain lesions or single hemispheric lesions (such as hemimegalencephaly). ${ }^{78}$ Subtle focal cortical dysplasias (FCD) may be missed on MRI early in the course of the illness. On the contrary, some FCDs may disappear as the white matter matures. FDG-PET may detect the FCD when MRI is normal. Longitudinal, repeated MRI and 
FDG-PET may be needed to pick up FCDs. ${ }^{74}$ In patients with TS with many cortical tubers or other children with widespread brain malformations, surgery is the option if seizure discharges are localized consistently to the same location. Data from the international TS registry showed that $4.2 \%$ of children with IS and TS underwent surgery. ${ }^{79}$ Porencephalic

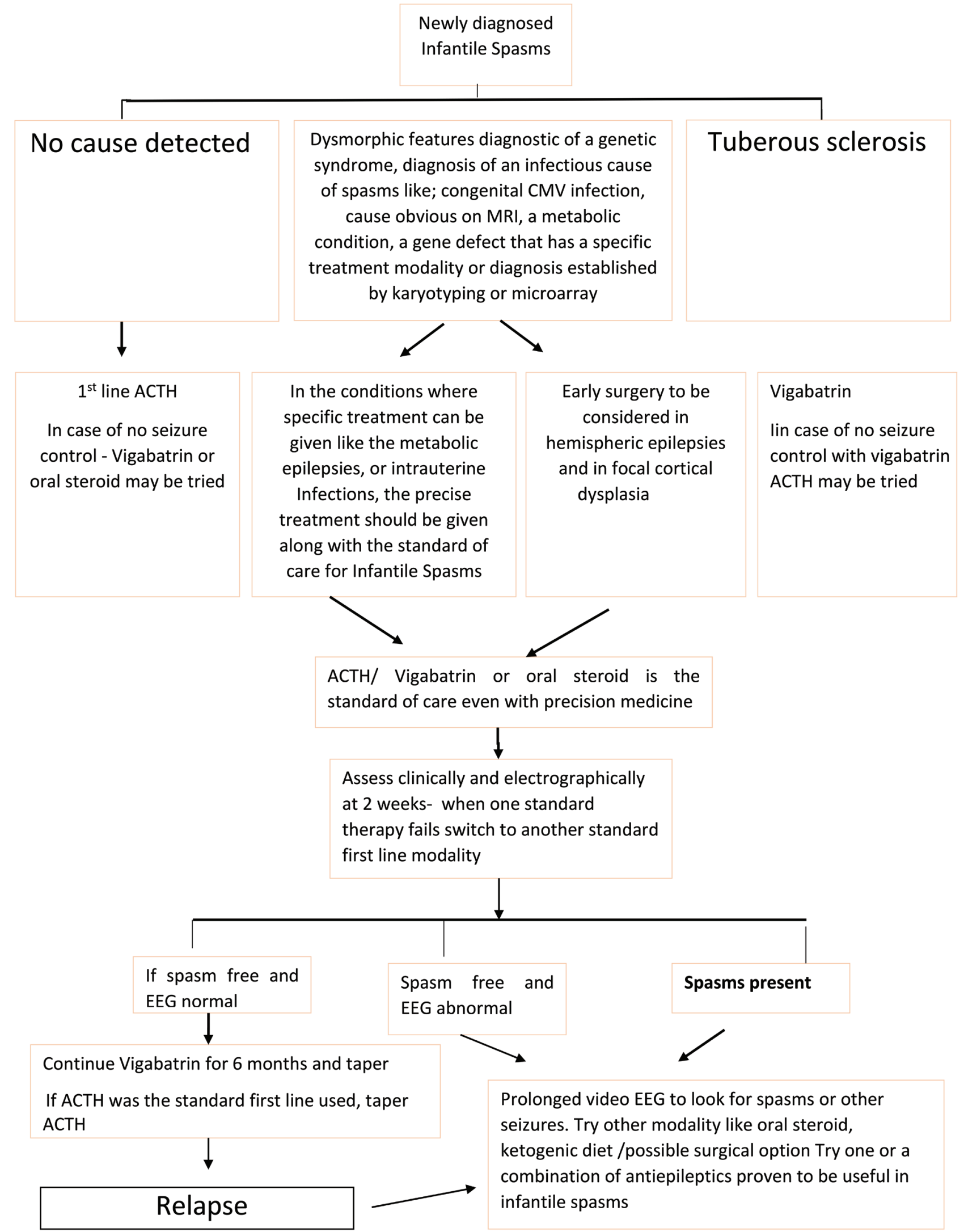

Fig. 2 Suggested treatment algorithm for infantile spasms. ACTH, adrenocorticotrophic hormone; CMV, cytomegalovirus; EEG, electroencephalogram; MRI, magnetic resonance imaging. 
cysts with concordant EEG localization can be marsupialized or fenestrated into the adjacent ventricle. The candidate is considered "ideal" when he has an MRI lesion or region of hypometabolism on PET not involving the motor or visual cortex. Minimally invasive surgery for focal lesions is the paradigm now and MRI-guided laser interstitial thermal therapy to ablate focal lesions has found success recently. ${ }^{80}$

In children with IS and hemimegalencephaly with contralateral hemiparesis, hemianopia and impaired fine finger movements, anatomical or functional hemispherectomy should be considered. This has resulted in both seizure control and developmental progression. If functional hemispherectomy is done earlier, chances of shift of function to the other hemisphere are more likely, especially with regard to language function, when the dominant hemisphere is megalencephalic. ${ }^{81}$ Early epilepsy surgery has led to better seizure outcome in other series also. ${ }^{82,83}$

\section{Issues in Management of Infantile Spasms in Developing Countries}

Reported hurdles in the management of IS in developing countries include resource limited setting, nonapproval of and no open marketing of vigabatrin (though FDA approved), unawareness that spasms are seizures, and financial burden of repeated hospital visits. ${ }^{84}$ Khreisat from Jordan and Kulsoom et al from Pakistan reported that the profile and outcome in their countries were similar to any other. ${ }^{85,86} \mathrm{~A}$ remarkable volume of work has been published from India on the effects of KD and oral steroids in children with IS. ${ }^{32,44,45}$ A study from Sri Lanka with very high dose of oral steroid has also raised hopes that this cheaper alternative could help children with IS in resource-limited countries. ${ }^{30}$

Immunosuppression when using the hormonal agents assumes greater importance in the developing countries, as exposure to tuberculosis is likely. A South African study found that none of the patients screened for tuberculosis prior to hormonal therapy showed a positive screen. ${ }^{87}$ There are currently no guidelines regarding screening for tuberculosis prior to hormonal therapy.

\section{Discussion}

Management of IS is yet to come of age. The flowchart in -Fig. 2 makes the current management guidelines for IS more manageable and definable. ACTH and vigabatrin have been promising in the treatment, with more favorable results with $\mathrm{ACTH}^{34}$ The behavioral and cognitive outcome even in children with control of seizures is poor., ${ }^{8,21}$ The end result of the ICISS trial has brought down hopes of combining hormonal treatment with vigabatrin. ${ }^{66}$

Once diagnosis of IS has been made, a proper history should be taken followed by a thorough physical examination to attempt to reach an etiological diagnosis. However, it is evident from studies in neurometabolic centers that prognosis for IS with an underlying neurometabolic disease is poor in spite of precision treatment. ${ }^{52}$ Knowing the etiology is also important in prognostication as cryptogenic
IS has shown better response to hormonal treatment. ${ }^{22,34} \mathrm{~A}$ recent, multicenter prospective database recruiting newly diagnosed IS has concluded that the most important factor that determines seizure outcome is early initiation of standard treatment even when the child has a known structural, metabolic, or genetic defect. ${ }^{34}$

ACTH should be considered over other standard-treatment modalities, unless the patient has TS. . $120-22,34$ Vigabatrin should possibly be the first standard therapy in children with TS. ${ }^{25-27}$ The other nonstandard treatments have insufficient evidence for use. ${ }^{16,34} \mathrm{High}$-dose ACTH currently has more evidence than low-dose ACTH. ${ }^{16}$ When vigabatrin and oral steroids are used, dose recommended is high. ${ }^{27,30-33,35}$ The possibility of combining hormonal treatment with vigabatrin has been set aside following the results of the ICISS trial. ${ }^{66}$

There is no clear guideline on when to evaluate the response to first-line standard treatment. Hussain in his 2018 review mandates change of the first-line treatment at 2 weeks if there is no remission. ${ }^{67}$ When the first-line standard treatment fails, evidence shows that another standard treatment (ACTH, oral steroid, or vigabatrin) is superior to the use of a nonstandard modality. ${ }^{61}$ The highest response rate was when the second standard-therapy had a different mechanism of action (ACTH to vigabatrin or vice versa). ${ }^{61}$

There is no consensus on the next step to be taken if both these first-line modalities fail as none of the other treatment modalities has been backed by robust evidence. ${ }^{16,34}$ Surgery as an option should be considered early in the course in children with a proven discrete focus. ${ }^{78,80-84}$

A positive short-term response to standard treatment is taken as seizure freedom and resolution of hypsarrhythmia at 2 weeks with no relapse up to 3 months, though late responders are documented. ${ }^{16,34}$ Hussain in his review recommends use of nonstandard modalities of treatment including topiramate, zonisamide, KD, valproate, felbamate, or cannabidiol when standard-modalities of treatment fail, though the AAN guidelines (2012) clearly do not recommend nonstandard therapy ${ }^{67}$

\section{Conclusion}

Evidence we have today, points to the use of standard modalities of treatment of IS (ACTH, oral steroids, or vigabatrin) with possibly more evidence in favor of ACTH. The standard modalities of treatment are best used sequentially, using a modality with a different mechanism of action as the second agent. Detecting the underlying etiology and treatment of the same though important should not deter one from starting one of the standard modalities of treatment.

\section{Authors' Contributions}

M.I. did literature review and manuscript writing. K.G.K. contributed to literature search and manuscript writing.

\section{Conflict of Interest}

None declared. 


\section{References}

1 Fisher RS, Cross JH, D'Souza C, et al. Instruction manual for the ILAE 2017 operational classification of seizure types. Epilepsia 2017;58(4):531-542

2 Cowan LD, Hudson LS. The epidemiology and natural history of infantile spasms. J Child Neurol 1991;6(4):355-364

3 Osborne JP, Lux AL, Edwards SW, et al. The underlying etiology of infantile spasms (West syndrome): information from the United Kingdom Infantile Spasms Study (UKISS) on contemporary causes and their classification. Epilepsia 2010;51(10):2168-2174

4 Michaud JL, Lachance M, Hamdan FF, et al. The genetic landscape of infantile spasms. Hum Mol Genet 2014;23(18):4846-4858

5 Weaving LS, Christodoulou J, Williamson SL, et al. Mutations of CDKL5 cause a severe neurodevelopmental disorder with infantile spasms and mental retardation. Am J Hum Genet 2004;75(6):1079-1093

6 Kalscheuer VM, Tao J, Donnelly A, et al. Disruption of the serine/threonine kinase 9 gene causes severe $\mathrm{X}$-linked infantile spasms and mental retardation. Am J Hum Genet 2003;72(6):1401-1411

7 Lee $\mathrm{HH}$, Hur YJ. Glucose transport 1 deficiency presenting as infantile spasms with a mutation identified in exon 9 of SLC2A1. Korean J Pediatr 2016;59(Suppl 1) :S29-S31

8 Iype M, Saradakutty G, Kunju PA, et al. Infantile spasms: a prognostic evaluation. Ann Indian Acad Neurol 2016;19(2):228-235

9 O'Callaghan FJ, Lux AL, Darke K, et al. The effect of lead time to treatment and of age of onset on developmental outcome at 4 years in infantile spasms: evidence from the United Kingdom Infantile Spasms Study. Epilepsia 2011;52(7):1359-1364

10 Wirrell EC, Shellhaas RA, Joshi C, Keator C, Kumar S, Mitchell WG; Pediatric Epilepsy Research Consortium. How should children with West syndrome be efficiently and accurately investigated? Results from the National Infantile Spasms Consortium. Epilepsia 2015;56(4):617-625

11 Hancock EC, Osborne JP, Edwards SW. Treatment of infantile spasms. Cochrane Database Syst Rev 2013; (6):CD001770

12 Riikonen R. Recent advances in the pharmacotherapy of infantile spasms. CNS Drugs 2014;28(4):279-290

13 Hamano S, Yamashita S, Tanaka M, Yoshinari S, Minamitani M, Eto Y. Therapeutic efficacy and adverse effects of adrenocorticotropic hormone therapy in west syndrome: differences in dosage of adrenocorticotropic hormone, onset of age, and cause. J Pediatr 2006;148(4):485-488

14 Hrachovy RA, Frost JD Jr, Glaze DG. High-dose, long-duration versus low-dose, short-duration corticotropin therapy for infantile spasms. J Pediatr 1994;124(5 Pt 1):803-806

15 Yanagaki S, Oguni H, Hayashi K, et al. A comparative study of high-dose and low-dose ACTH therapy for West syndrome. Brain Dev 1999;21(7):461-467

16 Go CY, Mackay MT, Weiss SK, et al; Child Neurology SocietyAmerican Academy of Neurology. Evidence-based guideline update: medical treatment of infantile spasms. Report of the Guideline Development Subcommittee of the American Academy of Neurology and the Practice Committee of the Child Neurology Society. Neurology 2012;78(24):1974-1980

17 Walker SD, Kälviäinen R. Non-vision adverse events with vigabatrin therapy. Acta Neurol Scand Suppl 2011;124(192):72-82

18 Krauss GL, Johnson MA, Miller NR. Vigabatrin-associated retinal cone system dysfunction: electroretinogram and ophthalmologic findings. Neurology 1998;50(3):614-618

19 Butler WH, Ford GP, Newberne JW. A study of the effects of vigabatrin on the central nervous system and retina of Sprague Dawley and Lister-Hooded rats. Toxicol Pathol 1987;15(2):143-148

20 Lux AL, Edwards SW, Hancock E, et al. The United Kingdom Infantile Spasms Study comparing vigabatrin with prednisolone or tetracosactide at 14 days: a multicentre, randomised controlled trial. Lancet 2004;364(9447):1773-1778
21 Lux AL, Edwards SW, Hancock E, et al; United Kingdom Infantile Spasms Study. The United Kingdom Infantile Spasms Study (UKISS) comparing hormone treatment with vigabatrin on developmental and epilepsy outcomes to age 14 months: a multicentre randomised trial. Lancet Neurol 2005;4(11):712-717

22 Darke K, Edwards SW, Hancock E, et al; trial steering committee on behalf of participating investigators. Developmental and epilepsy outcomes at age 4 years in the UKISS trial comparing hormonal treatments to vigabatrin for infantile spasms: a multi-centre randomised trial. Arch Dis Child 2010;95(5):382-386

23 Chiron C, Dumas C, Jambaqué I, Mumford J, Dulac O. Randomized trial comparing vigabatrin and hydrocortisone in infantile spasms due to tuberous sclerosis. Epilepsy Res 1997;26(2):389-395

24 Ahmed R. Comparative study of corticotrophin vs. vigabatrin therapy in infantile spasm. Pak J Med Sci 2007;23(1):141-144

25 Elterman RD, Shields WD, Mansfield KA, Nakagawa J; US Infantile Spasms Vigabatrin Study Group. Randomized trial of vigabatrin in patients with infantile spasms. Neurology 2001;57(8):1416-1421

26 Elterman RD, Collins SD, Shields D, Mansfield KA, Nakagawa J. Efficacy of vigabatrin in subjects with infantile spasms. Epilepsia 2005;46(S8):142

27 Elterman RD, Shields WD, Bittman RM, Torri SA, Sagar SM, Collins SD. Vigabatrin for the treatment of infantile spasms: final report of a randomized trial. J Child Neurol 2010;25(11):1340-1347

28 Sergott RC, Wheless JW, Smith MC, et al. Evidence-based review of recommendations for visual function testing in patients treated with vigabatrin. Neuroophthalmology 2010;34(1):20-35

29 O'Callaghan FJ, Edwards SW, Alber FD, et al; participating investigators. Safety and effectiveness of hormonal treatment versus hormonal treatment with vigabatrin for infantile spasms (ICISS): a randomised, multicentre, open-label trial. Lancet Neurol 2017;16(1):33-42

30 Wanigasinghe J, Arambepola C, Ranganathan SS, Sumanasena S. Randomized, single-blind, parallel clinical efficacy trial of oral prednisolone versus intramuscular corticotrophin: a 12 month assessment of spasm control in West Syndrome. Pediatr Neurol 2017;76:14-19

31 Hussain SA, Shinnar S, Kwong G, et al. Treatment of infantile spasms with very high dose prednisolone before high dose ACTH. Epilepsia 2014;55(1):103-107

32 Chellamuthu P, Sharma S, Jain P, Kaushik JS, Seth A, Aneja $\mathrm{S}$. High dose $(4 \mathrm{mg} / \mathrm{kg} /$ day $)$ versus usual dose $(2 \mathrm{mg} / \mathrm{kg} /$ day) oral prednisolone for treatment of infantile spasms: an open-label, randomized controlled trial. Epilepsy Res 2014; 108(8):1378-1384

33 Kossoff EH, Hartman AL, Rubenstein JE, Vining EP. Highdose oral prednisolone for infantile spasms: an effective and less expensive alternative to ACTH. Epilepsy Behav 2009;14(4):674-676

34 Knupp KG, Coryell J, Nickels KC, et al; Pediatric Epilepsy Research Consortium. Response to treatment in a prospective national infantile spasms cohort. Ann Neurol 2016;79(3):475-484

35 Ware TL, Mackay MT, Harvey AS, Freeman JL. Epileptic spasms: experience with a high-dose oral corticosteroid protocol. J Paediatr Child Health 2012;48(11):985-989

36 Hong AM, Turner Z, Hamdy RF, Kossoff EH. Infantile spasms treated with the ketogenic diet: prospective single-center experience in 104 consecutive infants. Epilepsia 2010;51(8):1403-1407

37 Kayyali HR, Gustafson M, Myers T, Thompson L, Williams M, Abdelmoity A. Ketogenic diet efficacy in the treatment of intractable epileptic spasms. Pediatr Neurol 2014;50(3):224-227 
38 Kang HC, Lee YJ, Lee JS, et al. Comparison of short- versus longterm ketogenic diet for intractable infantile spasms. Epilepsia 2011;52(4):781-787

39 Wang D, Pascual JM, Yang H, et al. Glut-1 deficiency syndrome: clinical, genetic, and therapeutic aspects. Ann Neurol 2005;57(1):111-118

40 Kossoff EH, Thiele EA, Pfeifer HH, McGrogan JR, Freeman JM. Tuberous sclerosis complex and the ketogenic diet. Epilepsia 2005;46(10):1684-1686

41 Kossoff EH, Zupec-Kania BA, Auvin S, et al; Charlie FoundationMatthew's FriendsPractice Committee of the Child Neurology Society. Optimal clinical management of children receiving dietary therapies for epilepsy: updated recommendations of the International Ketogenic Diet Study Group. Epilepsia Open 2018;3(2):175-192

42 Dressler A, Trimmel-Schwahofer P, Reithofer E, et al. The ketogenic diet in infants-advantages of early use. Epilepsy Res 2015;116:53-58

43 Dressler A, Benninger F, Trimmel-Schwahofer P, et al. Efficacy and tolerability of the ketogenic diet versus high-dose adrenocorticotropic hormone for infantile spasms: a single-center parallel-cohort randomized controlled trial. Epilepsia 2019;60(3):441-451

44 Sharma S, Sankhyan N, Gulati S, Agarwala A. Use of the modified Atkins diet in infantile spasms refractory to first-line treatment. Seizure 2012;21(1):45-48

45 Sharma S, Goel S, Jain P, Agarwala A, Aneja S. Evaluation of a simplified modified Atkins diet for use by parents with low levels of literacy in children with refractory epilepsy: a randomized controlled trial. Epilepsy Res 2016;127:152-159

46 Hussain SA, Shin JH, Shih EJ, et al. Limited efficacy of the ketogenic diet in the treatment of highly refractory epileptic spasms. Seizure 2016;35:59-64

47 Pietz J, Benninger C, Schäfer H, Sontheimer D, Mittermaier G, Rating D. Treatment of infantile spasms with high-dosage vitamin B6. Epilepsia 1993;34(4):757-763

48 Raffo E, Coppola A, Ono T, Briggs SW, Galanopoulou AS. A pulse rapamycin therapy for infantile spasms and associated cognitive decline. Neurobiol Dis 2011;43(2):322-329

49 Galanopoulou AS, Gorter JA, Cepeda C. Finding a better drug for epilepsy: the mTOR pathway as an antiepileptogenic target. Epilepsia 2012;53(7):1119-1130

50 Li M, Zhou Y, Chen C, et al. Efficacy and safety of mTOR inhibitors (rapamycin and its analogues) for tuberous sclerosis complex: a meta-analysis. Orphanet J Rare Dis 2019;14(1):39

51 Curatolo P, Bjørnvold M, Dill PE, et al. The role of mTOR inhibitors in the treatment of patients with tuberous sclerosis complex: evidence- based and expert opinions. Drugs 2016;76(5):551-565

52 Alrifai MT, AlShaya MA, Abulaban A, Alfadhel M. Hereditary neurometabolic causes of infantile spasms in 80 children presenting to a tertiary care center. Pediatr Neurol 2014;51(3):390-397

53 Salar S, Moshé SL, Galanopoulou AS. Metabolic etiologies in West syndrome. Epilepsia Open 2018;3(2):134-166

54 Fukuoka M, Kuki I, Kawawaki H, et al. Quinidine therapy for West syndrome with KCNTI mutation: a case report. Brain Dev 2017;39(1):80-83

55 Korman SH, Wexler ID, Gutman A, Rolland MO, Kanno J, Kure S. Treatment from birth of nonketotic hyperglycinemia due to a novel GLDC mutation. Ann Neurol 2006;59(2):411-415

56 Sfaello I, Castelnau P, Blanc N, Ogier H, Evrard P, Arzimanoglou A. Infantile spasms and Menkes disease. Epileptic Disord 2000;2(4):227-230

57 Dunin-Wasowicz D, Kasprzyk-Obara J, Jurkiewicz E, Kapusta M, Milewska-Bobula B. Infantile spasms and cytomegalovirus infection: antiviral and antiepileptic treatment. Dev Med Child Neurol 2007;49(9):684-692
58 Riikonen R, Donner M. ACTH therapy in infantile spasms: side effects. Arch Dis Child 1980;55(9):664-672

59 Kwon YS, Jun YH, Hong YJ, Son BK. Topiramate monotherapy in infantile spasm. Yonsei Med J 2006;47(4):498-504

60 Lee GM, Lee KS, Lee EH, Chung S. Short term outcomes of topiramate monotherapy as a first-line treatment in newly diagnosed West syndrome. Korean J Pediatr 2011;54(9):380-384

61 Knupp KG, Leister E, Coryell J, et al; Pediatric Epilepsy Research Consortium. Response to second treatment after initial failed treatment in a multicenter prospective infantile spasms cohort. Epilepsia 2016;57(11):1834-1842

62 Jones K, Snead OC II, Boyd J, Go C. Adrenocorticotropic hormone versus prednisolone in the treatment of infantile spasms post vigabatrin failure. J Child Neurol 2015;30(5):595-600

63 Baram TZ, Mitchell WG, Tournay A, Snead OC, Hanson RA, Horton EJ. High-dose corticotropin (ACTH) versus prednisone for infantile spasms: a prospective, randomized, blinded study. Pediatrics 1996;97(3):375-379

64 Kivity S, Lerman P, Ariel R, Danziger Y, Mimouni M, Shinnar S. Long-term cognitive outcomes of a cohort of children with cryptogenic infantile spasms treated with high-dose adrenocorticotropic hormone. Epilepsia 2004;45(3):255-262

65 Inui T, Kobayashi T, Kobayashi S, et al. Efficacy of long term weekly ACTH therapy for intractable epilepsy. Brain Dev 2015;37(4):449-454

66 O'Callaghan FJK, Edwards SW, Alber FD, et al; International Collaborative Infantile Spasms Study (ICISS) investigators. Vigabatrin with hormonal treatment versus hormonal treatment alone (ICISS) for infantile spasms: 18-month outcomes of an open-label, randomised controlled trial. Lancet Child Adolesc Health 2018;2(10):715-725

67 Hussain SA. Treatment of infantile spasms. Epilepsia Open 2018;3(Suppl, Suppl 2) :143-154

68 Mytinger JR, Quigg M, Taft WC, Buck ML, Rust RS. Outcomes in treatment of infantile spasms with pulse methylprednisolone. J Child Neurol 2010;25(8):948-953

69 Hassanzadeh Rad A, Aminzadeh V. Infantile spasms treated with intravenous methylprednisolone pulse. Iran J Child Neurol 2017;11(2):8-12

70 Millichap JG, Millichap JJ. Prediction of infantile spasms recurrence after ACTH therapy. Pediatr Neurol Briefs 2015;29(12):93

71 Yamada K, Toribe Y, Kimizu T, et al. Predictive value of EEG findings at control of epileptic spasms for seizure relapse in patients with West syndrome. Seizure 2014;23(9):703-707

72 Khatami A, Sell E, Aggag M, Miller E. Brain MRI findings in infantile spasm: outcome correlations in a patient cohort. Open J Med Imag 2016;6(3):80-92

73 Thomas B, Al Dossary N, Widjaja E. MRI of childhood epilepsy due to inborn errors of metabolism. Am J Roentgenol 2010;194(5):W367-74

74 Sakaguchi Y, Kidokoro H, Ogawa C, et al. Longitudinal findings of MRI and PET in West Syndrome with subtle focal cortical dysplasia. Am J Neuroradiol 2018;39(10):1932-1937

75 Chugani HT, Ilyas M, Kumar A, et al. Surgical treatment for refractory epileptic spasms: The Detroit series. Epilepsia 2015;56(12):1941-1949

76 Chugani HT, Luat AF, Kumar A, Govindan R, Pawlik K, Asano

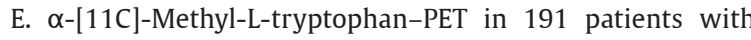
tuberous sclerosis complex. Neurology 2013;81(7):674-680

77 Eltze CM, Chong WK, Bhate S, Harding B, Neville BG, Cross JH. Taylor-type focal cortical dysplasia in infants: some MRI lesions almost disappear with maturation of myelination. Epilepsia 2005;46(12):1988-1992

78 Chipaux M, Dorfmüller G, Fohlen M, et al. Refractory spasms of focal onset-a potentially curable disease that should lead to rapid surgical evaluation. Seizure 2017;51:163-170

79 Nabbout R, Belousova E, Benedik MP, et al; TOSCA Consortium and TOSCA Investigators. Epilepsy in tuberous 
sclerosis complex: findings from the TOSCA study. Epilepsia Open 2018;4(1):73-84

80 Cobourn K, Fayed I, Keating RF, Oluigbo CO. Early outcomes of stereoelectroencephalography followed by MR-guided laser interstitial thermal therapy: a paradigm for minimally invasive epilepsy surgery. Neurosurg Focus 2018;45(3):E8, $10.3171 / 2018.6$

81 Peacock WJ, Wehby-Grant MC, Shields WD, et al. Hemispherectomy for intractable seizures in children: a report of 58 cases. Childs Nerv Syst 1996;12(7):376-384

82 Loddenkemper T, Holland KD, Stanford LD, Kotagal P, Bingaman W, Wyllie E. Developmental outcome after epilepsy surgery in infancy. Pediatrics 2007;119(5):930-935

83 Jonas R, Asarnow RF, LoPresti C, et al. Surgery for symptomatic infant-onset epileptic encephalopathy with and without infantile spasms. Neurology 2005;64(4):746-750
84 Gulati S, Jain P, Kannan L, Sehgal R, Chakrabarty B. The clinical characteristics and treatment response in children with West syndrome in a developing country: a retrospective case record analysis. J Child Neurol 2015;30(11):1440-1447

85 Khreisat WH. Clinical profile of infants with hypsarrhythmia. Acta Inform Med 2011;19(3):149-152

86 Kulsoom S, Ibrahim SH, Jafri SK, Moorani KN, Anjum M. Infantile Spasms: Clinical profile and treatment outcomes. Pak J Med Sci 2018;34(6):1424-1428

87 Keshave A, Yende-Zuma N, Mubaiwa L, Adhikari M. The clinical profile and outcome of children with West syndrome in KwaZulu-Natal Province, South Africa: a 10-year retrospective review. S Afr J Child Health 2017;11(3):135-140 doi 10.7196/ SAJCH.2017.v11i3.1300 